\title{
Intraepithelial and invasive squamous cell carcinoma of the conjunctiva: analysis of 60 cases
}

\author{
Murat Tunc, Devron H Char, Brooks Crawford, Theodore Miller
}

Department of Ophthalmology, University of California, San Francisco, USA M Tunc

Department of Ophthalmology, Radiation Oncology, the Francis I Proctor Foundation, University of California, and the Tumori Foundation, San Francisco, USA D H Char

Eye Pathology, University of California, San Francisco, USA

B Crawford

Pathology, University of California, San Francisco, USA T Miller

Correspondence to: Devron H Char, MD, Tumori Foundation, Suite 309, CPMC-Davies, 45 Castro Street, San Francisco, CA 94114, USA.

Accepted for publication 18 August 1998

\begin{abstract}
Aim-To evaluate the clinical features, treatment results, and recurrence rates in patients with either intraepithelial or invasive squamous cell carcinoma of the conjunctiva.

Methods-Retrospective analysis of $\mathbf{6 0}$ cases ( 22 conjunctival intraepithelial and 38 invasive squamous cell carcinomas) to determine patterns of clinical presentation, aetiological factors, and treatment results. The mean patient age was 64 years old. $70 \%$ of the patients were male. Patients were treated with a variety of therapies, depending on the degree of tumour involvement; most cases were treated with frozen section controlled excision and adjunctive cryotherapy. Modified eye wall resection or enucleation was done for intraocular invasion and exenteration was done for orbital involvement.
\end{abstract}

Results-Red eye (68\%) and ocular irritation $(57 \%)$ were the most common presenting symptoms. $44 \%$ of the patients had other eye findings consistent with extensive solar exposure. $20 \%$ of the patients had a history of malignant skin tumours. Visceral malignancies developed in $8 \%$. Scleral involvement was present in 14 $(37 \%)$, intraocular involvement in five $(13 \%)$, and orbital invasion in four (11\%) cases with invasive squamous cell carcinoma. After a mean follow up of 56 months (18-226 months) the rate of new or recurrent tumours was $4.5 \%$ for intraepithelial squamous carcinoma and $5.3 \%$ for invasive squamous cell carcinoma. No patient developed metastases or tumour related deaths.

Conclusion-Excision with intraoperative control of the surgical margins and adjunctive cryotherapy results in good tumour control rates.

(Br f Ophthalmol 1999;83:98-103)

Conjunctival squamous cell carcinoma (intraepithelial and invasive) is the most common conjunctival malignancy in the United States. ${ }^{12}$ The incidence of this neoplasm is between 1 and 2.8 per 100000 people per year and varies in different geographic locations. ${ }^{3}$ Epidemiological studies have shown that ultraviolet B radiation (290-320 nm) may be important in its pathophysiology. ${ }^{4}$ Ultraviolet $\mathrm{B}$ induced point mutations in the p53 tumour suppressor gene have been reported in other squamous cell carcinomas. ${ }^{6}$ Human papillo- mavirus (HPV) types 16 and 18 may also be important in tumour development. ${ }^{7-12}$

Intraepithelial squamous carcinoma (also known as conjunctival intraepithelial neoplasia, or conjunctival intraepithelial neoplasia, previously known as Bowen's disease) and invasive squamous cell carcinoma of the conjunctiva are histologically differentiated according to the invasion of epithelial basement membrane. In invasive squamous cell carcinoma cells infiltrate through the basement membrane and invade the substantia propria. ${ }^{1}$ Although intraepithelial squamous carcinoma may progress to invasive squamous cell carcinoma, the former lesions are localised in the epithelium. ${ }^{12}$

Clinically these tumours most commonly arise in the interpalpebral area of the perilimbal conjunctiva. The growth may be in a nodular, gelatinous, flat superficial leucoplakic, or diffuse invasive fashion. These tumours may present as localised slowly growing lesions that mimic benign conjunctival degenerations and sometimes coexist with pinguecula and pterygia. ${ }^{12}$ Diffuse tumours in older patients may be misdiagnosed as a chronic unilateral conjunctivitis..$^{14}$ Bowman's layer usually is a barrier to invasive disease..$^{15}$ Rarely the initial lesion appears on palpebral conjunctiva. ${ }^{14}$ Long term neglected invasive lesions may spread into the globe or orbit. ${ }^{16-19}$

The treatment options for conjunctival epithelial malignancies include tumour removal with or without cryotherapy, radiotherapy and topical chemotherapy. ${ }^{20-28}$ The reported incidence of recurrence after initial treatment is quite variable. Previous reports reveal high recurrence rates after simple surgical excision. ${ }^{21}{ }^{29-31}$ Invasive disease may cause intraocular and orbital involvement with eye loss. ${ }^{161721}$

In order to evaluate the clinical features, recurrence rates, and the outcome of treatment modalities we performed a retrospective analysis of our cases.

\section{Patients and methods}

Sixty eyes of 59 patients with pathological confirmation of either intraepithelial or invasive squamous cell carcinoma were included in this study. These patients were managed by one of us (DHC) between 1977 and 1996. Benign conjunctival tumours and other types and variants of conjunctival malignancies were excluded. Patients with less than 18 months of follow up were also excluded from this analysis. Forty patients, referred either for initial treatment or after an outside biopsy, showed tumour at the resection margins. Nineteen 
patients were referred for recurrences after primary treatment. Patient data were analysed for presenting symptoms, possible aetiological factors, clinical features, association of other malignancies, tumour shape and location, treatment modalities, clinical course, recurrence rates, and visual outcome.

We excised all lesions with frozen section control in the operating room. In all cases the scleral surface and three sides of surrounding cornea and conjunctiva were treated with adjunctive double freeze thaw cryotherapy. If scleral invasion was suspected at surgery, partial thickness sclera was sent for frozen section histopathological examination. In cases with histologically positive scleral margins a lamellar sclerectomy was performed, and usually the site was covered with an allogeneic or autologous scleral graft. After frozen sections confirmed clear surgical margins, the area of excised conjunctiva was reconstructed either with an advancement conjunctival flap, autologous conjunctiva, or buccal mucosal grafts, depending on the shape, size and location of the defect.

If more than $40 \%$ of the corneal surface was involved by the tumour, after resection with adjunctive cryotherapy, an autologous limbal graft from the contralateral eye was placed. Enucleation was performed for patients with diffuse intraocular involvement. In a few patients with small localised intraocular invasion without diffuse anterior chamber seeding, we performed a modified eye wall resection by locally resecting the tumour that involved the sclera and uvea. Anterior exenteration was done for tumours infiltrating the orbit.

Patients were followed either by us or in conjunction with their local ophthalmologists. The follow up period was between 18 and 226 months with a mean of 56 months. No patient was lost to follow up or developed metastases.

\section{Results}

Histopathologically there were 22 intraepithelial tumours and 38 invasive squamous cell carcinomas. The right eye was involved in 27 patients, and left in 31. Squamous cell carcinoma of the conjunctiva was bilateral in one patient. The patients were between 26 and 84 years old with a mean age of 64 years old. There was a male predominance ( $41 \mathrm{men}$ and 18 women). Fifty three patients were white, four were Hispanic, and two were Asian. Most of the patients were retired at the time of diagnosis; 14 had a previous outdoor and 45 an indoor occupation.

The most common presenting symptoms were red eye in $41(68 \%)$ and ocular irritation in $34(57 \%)$ patients. Other complaints such as decreased vision, itching, and photophobia were also present in six patients. Two patients had no complaints and the lesion was detected during a routine eye examination. Almost half the patients (26 of 59) had another ocular finding associated with extensive sun exposure such as pterygium, pinguecula, solar elastosis, or nuclear sclerosis.

Four of $22(18 \%)$ intraepithelial neoplasia and eight of $37(22 \%)$ squamous cell carci- noma patients had a history of a malignant cutaneous tumour. Eleven were basal cell carcinomas and one was a cutaneous epidermoid carcinoma. Two patients with intraepithelial tumours $(9 \%)$ and three patients with invasive squamous cell carcinoma (8\%) developed visceral malignancies after the diagnosis of the conjunctival tumour. Two patients had colon carcinomas, and the three other patients each developed lung, breast, and renal cell carcinomas. None of these patients with a second visceral malignancy had a known cancer diathesis.

The conjunctival lesion was located on the temporal limbal conjunctiva in $50 \%$ of cases. Thirteen cases $(59 \%)$ with intraepithelial neoplasia and 21 cases (55\%) with invasive carcinoma had corneal involvement. Intraepithelial tumours had a limbal involvement of less than three clock hours in $18(82 \%)$, three to six clock hours in three $(14 \%)$, and more than six clock hours in one $(4 \%)$ case. In invasive squamous cell carcinoma, limbal involvement was less than three clock hours in 23 $(61 \%)$, between three and six clock hours in 10 $(26 \%)$, and more than six clock hours in five $(13 \%)$ cases.

Intraepithelial squamous carcinoma lesions were nodular gelatinous (elevated, focal masses with a vascular, mulberry appearance) in $11(50 \%)$, flat leucoplakic in nine $(41 \%)$, and superficial diffuse in two $(9 \%)$ cases. The clinical appearance of invasive squamous cell carcinoma lesions were nodular gelatinous in 16 $(42 \%)$, flat, localised leucoplakic in six $(16 \%)$, and diffuse infiltrative in $16(42 \%)$ cases. The lesion had intrinsic tumour and/or feeder vessels in 14 cases (64\%) with intraepithelial tumours, and in 25 cases (66\%) with invasive squamous cell carcinoma. Secondary pigmentary changes were present in two intraepithelial and one invasive squamous cell carcinoma lesions.

We primarily managed 14 of 22 intraepithelial squamous carcinoma cases; eight patients were referred because of recurrences after initial treatment elsewhere. Initial treatment modalities are summarised in Table 1 . In all cases we performed excision with frozen section control and adjunctive cryotherapy. In one of eight cases referred for recurrence, a second recurrence developed 14 months later

Table 1 Initial diagnosis and management of the patients

\begin{tabular}{lccccc}
\hline \multirow{2}{*}{$\begin{array}{l}\text { Initial } \\
\text { management }\end{array}$} & \multicolumn{2}{c}{ Initial diagnosis } & & \multicolumn{2}{c}{ Initial treatment centre } \\
\cline { 2 - 3 } \cline { 5 - 6 } \cline { 5 - 6 } & CINt & SCC & & UCSF $\neq$ & Others \\
\hline E & 6 & 5 & & 0 & 11 \\
E+C & 16 & 9 & & 22 & 3 \\
E+C+LKS & 0 & 11 & & 11 & 0 \\
E+C+L & 0 & 4 & & 4 & 0 \\
E+RT & 0 & 4 & & 0 & 4 \\
E+TCA & 0 & 2 & & 0 & 2 \\
EN & 0 & 1 & & 1 & 0 \\
EXE & 0 & 2 & & 2 & 0 \\
Total & 22 & 38 & & 40 & 20
\end{tabular}

${ }^{\star} \mathrm{E}=$ total excision; $\mathrm{C}=$ cryotherapy; $\mathrm{LKS}=$ lamellar keratosclerectomy; LT=limbal transplantation; RT=radiotherapy; TCA=topical cytotoxic agents; EN=enucleation; $\mathrm{EXE}=$ exenteration.

+CIN=conjunctival intraepithelial neoplasia; $\mathrm{SSC}=$ squamous cell carcinoma of the conjunctiva.

$\ddagger$ UCSF=University of California, San Francisco. 
Table 2 Postoperative complications

\begin{tabular}{llll}
\hline Treatment & Cases $(n)$ & Postoperative complications & No \\
\hline Excision + cryotherapy & 27 & Pannus & Dellen \\
& & Corneal scar formation & 2 \\
Excision + cryotherapy + & \multirow{2}{*}{14} & Hypertropia & 1 \\
lamellar sclerectomy & & Descemetocele & 1 \\
Excision + cryotherapy + & \multirow{2}{*}{8} & Astigmatism & 1 \\
free mucosal grafts & & Contraction of the graft & 1 \\
\hline
\end{tabular}

${ }^{\star}$ Pannus or corneal scar was out of visual axis and did not require additional treatment.

†Symblepharon was mild and did not require secondary repair in three of the cases.

and required retreatment. After a mean follow up of 56 months (18-223 months) the overall recurrence rate was one in $22(4.5 \%)$ for intraepithelial tumours. The last posttreatment visual acuity was better than $20 / 40$ in 18 of 22 , and better than $20 / 60$ in the remaining four patients.

We performed initial therapy on 27 of the 38 conjunctival invasive squamous cell carcinoma cases; treatment modalities are summarised in Table 1. Scleral involvement was present in 14 $(37 \%)$ of 38 invasive cases. Five patients $(13 \%)$ had intraocular involvement of the anterior chamber angle. Four (11\%) cases had orbital involvement at the time of the referral.

Eleven cases were referred with recurrent tumours. Five of the recurrent cases had previous surgical excision, four had excision and radiotherapy, and two had prior excision with adjunctive topical cytotoxic therapy. The mean interval between the initial management and the diagnosis of recurrence was 18 months. In patients referred with recurrent disease we performed excision with frozen section control and adjunctive cryotherapy in five patients; four of these also had lamellar keratosclerectomy with scleral and/or limbal grafts. In the other six cases with more extensive tumours, two each had enucleation, exenteration, and modified eye wall resection.

Two of the invasive squamous cell carcinoma cases we initially managed developed recurrences. Both of these patients had been referred to us with positive tumour margins. We had initially managed these cases with frozen section controlled excision and cryotherapy. The second case was more extensive and also required a lamellar keratosclerectomy. Both of these cases underwent a second excision with intraoperative control of surgical margins and adjunctive cryotherapy. Neither has recurred within a follow up of 48 months.

None of the cases recurred after eye wall resection, enucleation, or exenteration. Our overall recurrence rate for conjunctival squamous cell carcinoma was two of $38(5.3 \%)$, with a mean follow up of 55 months (18-226 months). In both recurrent cases we obtained tumour control. No patients developed metastatic disease or were lost to follow up.

Visual results of invasive conjunctival carcinoma were related to the tumour extent and other ocular disease. The last visual acuity was better than 20/40 in 22 and between 20/40 and $20 / 80$ in six cases who retained their eyes. In two of six cases in the latter group decreased vision was secondary to the tumour or the treatment. In two patients, the vision was less than 20/100 because of an age related cataract or aphakic bullous keratopathy. Seven eyes were lost due to intraocular or orbital invasion. One referred case had lost his vision due to previous radiotherapy and we performed an enucleation, as the eye was blind and painful.

After surgical removal and cryotherapy, pannus formation developed in two cases; in neither case did this cause visual loss. Eight cases were treated with mucosal grafts and minor degrees of symblepharon developed in four; one case required repair. In one case we resected the insertion of the inferior rectus because of tumour invasion. This case developed hypertropia and required a secondary muscle surgery. Surgical complications are summarised in Table 2.

\section{Discussion}

Conjunctival epithelial malignancies are more common in elderly and male patients, but may develop at a younger age especially in association with xeroderma pigmentosum or immunodeficiency. ${ }^{17}{ }^{32-35}$ None of our cases had these latter predisposing factors. Some reports have noted a younger age in intraepithelial cases compared with invasive squamous cell carcinoma, but we did not observe this in our series. ${ }^{21}{ }^{30}$ In line with previous reports we noted a male predominance probably due to increased occupational exposure to sunlight. ${ }^{21} 23303136-38$ In almost half of our patients other solar eye changes were noted.

Cutaneous and visceral malignancies in association with conjunctival epithelial tumours have been reported. ${ }^{1} 17303638$ Erie and associates ${ }^{30}$ reported $13 \%$ of patients had a history of malignant skin tumours. Twelve $(20 \%)$ of our patients had skin malignancies; 11 were basal cell and one was an epidermoid carcinoma. Bowen's disease or in situ cutaneous carcinomas have been thought to be associated with internal cancer but recent population based data failed to show this association; thus, most investigators no longer use this terminology. ${ }^{39}$ Visceral malignancies were noted in five $(8 \%)$ of our cases, in agreement with other reports. ${ }^{17} 3036$ In an epidemiological investigation of uveal melanoma patients, we noted that over $10 \%$ had another malignancy. ${ }^{40}$ In that analysis we noted that this was not significantly above age matched controls and the mean age was similar in conjunctival malignancies. ${ }^{40}$

The importance of HPV types 16 and 18 in the pathophysiology of conjunctival carcinoma is uncertain. ${ }^{91141-44}$ Some previous reports indicate the association of human papillomavirus 16 (HPV-16) with some cases of bilateral conjunctival dysplasia. ${ }^{72}$ In some studies as many as $77 \%$ of cases have had immunohistogenic evidence of these viruses. ${ }^{7-1242-44}$ Other authors have noted HPV in a number of non-malignant solar related conjunctival lesions. ${ }^{45}$ We did not perform a controlled study of HPV in our patients' tumours.

Conjunctival squamous cell neoplasms are more frequent in immunocompromised patients. ${ }^{10}{ }^{33-35}$ It was estimated that the relative 
risk of conjunctival epithelial malignancies increased 13-fold in patients with acquired immune deficiency syndrome (AIDS). ${ }^{1033-35}$ Some investigators have suggested that as many as $50 \%$ of patients, less than 50 years old, with a conjunctival neoplasm may have AIDS. ${ }^{34}{ }^{35}$ None of our younger patients had a history of, or developed, immune deficiency. While we are surprised by the lack of AIDS patients in our study cohort, it may reflect referral bias, false negative diagnosis, or other unknown factors.

Squamous cell carcinoma of the palpebral conjunctiva is uncommon; misdiagnosis often delays treatment and increases morbidity. ${ }^{214} 4146$ Palpebral conjunctival involvement occurred in six of our cases and two required an anterior exenteration because of orbital involvement.

The cornea was involved in over half of our cases. In cases that involved the cornea we removed the involved epithelium with a scalpel; others have reported the use of alcohol ${ }^{25}$ or excimer laser. ${ }^{47}$ Bowman's layer is usually a natural barrier and if possible should be left intact; deeper keratectomy and extensive cryotherapy may cause corneal scar formation, dellen, and astigmatism. ${ }^{20} 48$

Scleral involvement is a risk factor for both tumour recurrence and intraocular invasion. ${ }^{172530}$ Buuns and associates ${ }^{25}$ described scleral involvement in $21 \%$ of cases and it was present in $14(37 \%)$ of our invasive cases. It is difficult to accurately delineate the deep tumour margins with a very small piece of tissue that has been further reduced in size to determine the tumour status of its horizontal edges. Given the histological sampling limits with conjunctival tumours, we routinely treat the scleral base and conjunctival margins with double freeze cryotherapy. Most cases referred to us with recurrent tumour had previous excisions without cryotherapy.

Intraocular invasion has been reported between $2 \%$ and $8 \%$ of cases. ${ }^{117}{ }^{170}$ We noted a slightly higher incidence (13\%), probably reflecting a tertiary referral practice. Deep corneal stromal invasion and involvement of anterior chamber structures suggest intraocular invasion. ${ }^{17} 2249$ Intraocular invasion may also present with iritis, glaucoma, retinal detachment, or rupture of the globe. ${ }^{43}{ }^{49}$ Gonioscopy should be performed in all cases to determine whether diffuse peripheral anterior synechiae are present which are a hallmark of intraocular invasion. A tumour with small localised intraocular invasion without diffuse anterior chamber seeding may be successfully treated with a modified eye wall resection. ${ }^{22}{ }^{41}$

Previous studies reported orbital invasion in $12-16 \%$ of invasive cases. ${ }^{173050}$ We noted a similar incidence and anterior orbital exenteration was necessary in all of them. Local invasion is the most prevalent mechanism of tumour spread. ${ }^{17}{ }^{17950}$ Metastases are rare, and the first site of extraocular involvement is regional lymph nodes. ${ }^{17} 184546-51$

Radiotherapy and topical cytotoxic agents have been used to treat some conjunctival carcinomas. ${ }^{23} 24$ 26-28 52 Kearsley and associates ${ }^{23}$ reported 140 invasive cases treated with strontium-90 radiotherapy with a recurrence rate of $2.3 \%$. Complications after strontium-90 irradiation include scleral necrosis and cataract formation; external beam radiation may produce a dry painful eye and visual loss due to radiation vasculopathy. ${ }^{1}{ }^{23}{ }^{52}$ In our series three patients were referred after radiation treatment failures. Radiation has a limited role in the management of this neoplasm. Our control rate with surgery has been excellent. In diffuse tumours, radiation can destroy the reproductive integrity of the malignancy, but radiation damage may result in a staged anterior exenteration.

There are limited data on topical cytotoxic therapy. ${ }^{24}$ 26-28 Frucht-Pery and Rozenman ${ }^{24}$ reported on three cases. Yeatts and associates ${ }^{26}$ treated six conjunctival intraepithelial neoplasia cases with topical 5-fluorouracil; five responded well but one progressed and required exenteration. Good short term conjunctival intraepithelial neoplasia response has been reported after topical $0.04 \%$ mitomycin therapy. ${ }^{527285354}$ In our series two eyes with squamous cell carcinoma were treated elsewhere with excision and topical cytotoxic agents for about 1 month (5-fluorouracil and cyclosporin A) and recurred in 12-18 months. In a compendium of recent published series there is a paucity of long term follow up with topical mitomycin. A few intraepithelial and invasive cases have failed and a study of more patients with longer follow up is needed. Since local failures, as discussed below, have had a mean time to recurrence between 8 and 22 months, the long term efficacy of topical agents is uncertain.

Surgical complications include corneal scarring, symblepharon, ocular hypotony, and iris atrophy. ${ }^{20} 48$ Most cases referred to us by corneal specialists had large diffuse tumours. As a result, we required larger buccal as opposed to conjunctival autologous grafts. Our most common surgical complication was symblepharon; only one case required secondary symblepharon correction. In contrast with some reports, ${ }^{20}{ }^{48}$ we did not observe hypotony after double freeze thaw cryotherapy.

Visual results after our treatment were excellent. Only two cases with squamous cell carcinoma had low vision $(<20 / 60)$ due to tumour or treatment. Previous reports ${ }^{20} 5556$ demonstrate that if the tumour involves more than $40 \%$ of the cornea, excision combined with adjunctive cryotherapy resulted in persistent corneal inflammation, intrastromal neovascularisation, and poor vision. In such cases limbal grafts improved epithelial healing and prevented ocular surface problems. ${ }^{55}$

Recurrence of conjunctival epithelial malignancies depends on the status of surgical margins. ${ }^{29-31} 36$ Simple excision of conjunctival intraepithelial or invasive neoplasia is associated with a $24-50 \%$ recurrence rate. ${ }^{117} 293036$ Several histological features are important for tumour recurrence; however, even in cases with milder degrees of atypia, careful assessment of histological margins is mandated. ${ }^{57}$ Tabin and associates $^{29}$ excised intraepithelial tumours without intraoperative control of surgical 
margins; $25 \%$ had positive margins and incompletely excised cases developed twice as many recurrences as those with tumour free margins. ${ }^{29}$ We controlled the surgical margins by frozen sections and applied adjunctive cryotherapy. Our recurrence rates, $4.5 \%$ for intraepithelial tumours and $5.3 \%$ for squamous cell carcinoma, are lower than most of the previous reports. ${ }^{1729-3136}$ Erie and associates ${ }^{30}$ reported a recurrence rate of $41 \%$ in squamous cell carcinoma and $23.5 \%$ in conjunctival intraepithelial neoplasia after local excision with a follow up of 6 months to 39 years. Irvine $^{31}$ reported a $10 \%$ local recurrence rate but half of the cases had either no, or less than 1 year, of follow up. Follow up examinations for longer than 12 months are necessary as the mean time to recurrence has been reported as between 8 and 22 months. ${ }^{1723303136}$ Buuns and associates ${ }^{25}$ reported no recurrence in 19 squamous cell carcinoma cases with microscopically controlled excision, a modification of Mohs' micrographic surgery, but some of these cases had only 6 months of follow up and four of 19 required a second operation.

Conjunctival squamous cell neoplasms can cause significant ocular morbidity. Early diagnosis and intervention can prevent major eye damage. Surgery with control of margins and adjunctive cryotherapy has a very high success rate; technical modifications may further reduce ocular damage, although more long term follow up is necessary to determine the optimal role for some of these newer treatment options.

1 Lee GA, Hirst LW. Ocular surface squamous neoplasia. Surv Ophthalmol 1995;39:429-49.

2 Grossniklaus HE, Green WR, Luckenbach M, et al. Conjunctival lesions in adults. Cornea 1987;6:87-116.

3 Lee GA, Hirst LW. Incidence of ocular surface dysplasia in metropolitan Brisbane. Arch Ophthalmol 1992;110:525-7.

4 Newton R, Ferlay J, Reeves G, et al. Effect of ambient solar ultraviolet radiation on incidence of squamous cell carcinoma of the eye. Lancet 1996;347:1450-1.

5 Lee GA, Williams G, Hirst LW, et al. Risk factors in the development of ocular surface epithelial dysplasia. Ophthalmology 1994;101:360-4.

6 Brash DE, Rudolph JA, Simon JA, et al. A role for sunlight in skin cancer: UV-induced p53 mutations in squamous in skin cancer: UV-induced p53 mutations in squamous

7 Odrich MG, Jakobiec FA, Lancaster WD, et al. A spectrum of bilateral squamous conjunctival tumors associated with human papillomavirus type 16. Ophthalmology 1991;98: 628-35.

8 Lauer SA, Malter JS, Meier R. Human papillomavirus type-18 in conjunctival intraepithelial neoplasia. $\mathrm{Am} \mathscr{F}$ Ophthalmol 1990;110:23-7.

9 McDonnell JM, McDonnell PJ, Sun YY. Human papillomavirus DNA in tissues and ocular surface swabs of patients with conjunctival epithelial neoplasia. Invest Ophthalmol Vi Sci 1992;33:184-9.

10 Lewallen S, Shroyer KR, Keyser RB, et al. Aggressive conjunctival squamous cell carcinoma in three young Africans. Arch Ophthalmol 1996;114:215-18.

11 Saegusa M, Takano Y, Hashimura M, et al. HPV type-16 in conjunctival and junctional papilloma, dysplasia, and conjunctival and junctional papilloma, dysplasia, and

12 Newton R. A review of the aetiology of squamous cell carciNewton R. A review of the aetiology of squamous cell carci-
noma of the conjunctiva. Br f Cancer 1996;74:1511-13.

13 Khalil MK, Pierson RB, Mihalovitis H, et al. Intraepithelial neoplasia of the bulbar conjunctiva clinically presenting as diffuse papillomatosis. Can f Ophthalmol 1993;28:287-90. 14 Goldberg SH, Riedy DK, Lanzillo JH. Invasive squamous Clin Exp Ophthalmol 1993;231:246-8.

15 Cha SB, Shields CL, Shields JA, et al. Massive precorneal extension of squamous cell carcinoma of the conjunctiva. Cornea 1993;12:537-40.

16 Glasson WJ, Hirst LW, Axelsen RA, et al. Invasive squamous cell carcinoma of the conjunctiva. Arch Ophthalmol 1994;112:1342-5.

17 Iliff WJ, Marback R, Green R. Invasive squamous cell carcinoma of the conjunctiva. Arch Ophthalmol 1975;93:11912.
18 Seregard S, Kock E. Squamous spindle cell carcinoma of the conjunctiva. Acta Ophthalmol Scand 1995;73:464-6.

19 Schubert HD, Farris RL, Green WR. Spindle cell carcinoma of the conjunctiva. Graefes Arch Clin Exp Ophthalmol 1995;233:52-5.

20 Fraunfelder FT, Wingfield D. Management of intraepithelial conjunctival tumors and squamous cell carcinomas. $\mathrm{Am}$ f Ophthalmol 1983;95:359-63.

21 Ni C, Searl SS, Kriegstein HJ, et al. Epibulbar carcinoma. Int Ophthalmol Clin 1982;22:1-33.

22 Char DH, Crawford JB, Howes EL, et al. Resection of intraocular squamous cell carcinoma. $\mathrm{Br} f$ Ophthalmol 1992;76:123-5.

23 Kearsley JH, Fitchew RS, Taylor RGS. Adjunctive radiotherapy with strontium- 90 in the treatment of conjunctival squamous cell carcinoma. Int $\mathcal{F}$ Radiat Oncol Biol Phys 1987;14:435-43.

24 Frucht-Pery J, Rozenman Y. Mitomycin C therapy for corneal intraepithelial neoplasia. Am f Ophthalmol 1994; 117:64-8.

25 Buuns DR, Tse DT, Folberg R. Microscopically controlled excision of conjunctival squamous cell carcinoma. Am $\mathcal{7}$ Ophthalmol 1994;117:97-102.

26 Yeatts RP, Ford JG, Stanton CA, et al. Topical 5-fluorouracil in treating epithelial neoplasia of the conjunctiva and cornea. Ophthalmology 1995;102:1338-44.

27 Wilson MW, Hungerford JL, George SM, et al. Topical mitomycin $\mathrm{C}$ for the treatment of conjunctival and corneal epithelial dysplasia and neoplasia. Am $f$ Ophthalmol 1997;124:303-11.

28 Heigle TJ, Stulting RD, Palay DA. Treatment of recurrent conjunctival epithelial neoplasia with topical mitomycin C. Am $\mathcal{F}$ Ophthalmol 1997;124:397-9.

29 Tabin G, Levin S, Snibson G, et al. Late recurrences and the necessity for long-term follow-up in corneal and conjunctival intraepithelial neoplasia. Ophthalmology 1997;104:48592.

30 Erie JC, Campbell RJ, Liesegang TJ. Conjunctival and corneal intraepithelial neoplasia. Ophthalmology 1986;93:17683.

31 Irvine AR. Dyskeratotic epibulbar tumors. Trans Am Ophthalmol Soc 1963;61:243-73.

32 Hertle RW, Durso F, Metzler JP, et al. Epibulbar squamous cell carcinomas in brothers with xeroderma pigmentosa. $\mathcal{F}$ Pediatr Ophthalmol Strabismus 1991;28:350-3.

33 Margo CE, Mack W, Guffey JM. Squamous cell carcinoma of the conjunctiva and human immunodeficiency virus infection. Arch Ophthalmol 1996;114:349.

34 Waddell KM, Lewallen S, Lucas SB, et al. Carcinoma of the conjunctiva and HIV infection in Uganda and Malawi. $\mathrm{BrF}$ Ophthalmol 1996;80:50350-8.

35 Karp CL, Scott IU, Chang TS, et al. Conjunctival intraepithelial neoplasia: a possible marker for human immunodeficiency virus infection. Arch Ophthalmol 1996;114:257-61.

36 Seitz B, Fischer M, Holbach LM, et al. Differentialdiagnose und Prognose bei 112 exzidierten epibulbõren epithelialen Tumoren. Klin Monatsbl Augenheilkd 1995;207:239-46.

37 Kripke ML. Ultraviolet radiation and immunology: something new under the sun-presidential address. Cancer Res 1994;54:6102-5.

38 Karagas MR, Stukel TA, Greenberg ER, et al. Risk of subsequent basal cell carcinoma and squamous cell carcinoma of the skin among patients with prior skin cancer. $7 A M A$ 1992;267:3305-30.

39 Chute CG, Chuang TY, Bergstralh EJ, et al. The subsequent risk of internal cancer with Bowen's disease. $\mathcal{F A M A} 1991$; 266:816-19.

40 Holly EA, Aston DA, Ahn DK, et al. No excess prior cancer in patients with uveal melanoma. Ophthalmology 1991;98: 608-11.

41 Char DH. Conjunctival malignancies. In: Char DH. Clinical ocular oncology. 2nd ed. Philadelphia: Lippincott-Raven,
1997:60-86.

42 McDonnell PJ, McDonnell JM, Kessis T, et al. Detection of human papillomavirus type 6/11 DNA in conjunctival papillomas by in situ hybridization with radioactive probes. Hum Pathol 1987;18:115-19.

43 Burk RD, Kadish AS. Treasure hunt for human papillomaviruses in nonmelanoma skin cancers. F Natl Cancer Inst 1996;88:781-2.

44 Tuppurainen K, Raninen A, Kosunen O, et al. Squamous cell carcinoma of the conjunctiva. Acta Ophthalmol Scand 1992;70:248-54.

45 Karcioglu ZA, Issa TM. Human papilloma virus in neoplastic and non-neoplastic conditions of the external eye. $\mathrm{Br} \mathcal{F}$ Ophthalmol 1997;81:595-8.

46 Cha SB, Shields JA, Shields CL, et al. Squamous cell carcinoma of the conjunctiva. Int f Ophthalmol Clin 1993;33:1924

47 Heffler KF. Tumors of the cornea and conjunctiva. Curr Opin Ophthalmol 1995;6:32-8.

8 Peksayar G, Soyturk MK, Demiryont M. Long term results of cryotherapy on malignant epithelial tumors of conjunctiva. Am F Ophthalmol 1989;107:337-49.

49 Wexler SA, Wallow IHL. Squamous cell carcinoma of the conjunctiva presenting with intraocular extension. Arch Ophthalmol 1985;103:1175-7.

50 Johnson TE, Tabbara KF, Weatherhead RG, et al. Secondary squamous cell carcinoma of the orbit. Arch Opondary squamous cell

51 Tabbara KF, Kersten R, Daouk N, et al. Metastatic squamous cell carcinoma of the conjunctiva. Ophthalmology 1988;95:318-21. 
52 Zehetmayer M, Menapace R, Kulnig W. Combined local excision and brachytherapy with ruthenium-106 in the treatment of epibulbar malignancies. Ophthalmologica

53 Frucht-Pery J, Sugar J, Baum J, et al. Mitomycin C treatment for conjunctival-corneal intraepithelial neoplasia. Ophthalmology 1997;104:2085-93.

54 Midena E, Boccato P, Angeli CD. Conjunctival squamous cell carcinoma treated with topical 5-fluorouracil. Arch Ophthalmol 1997;115:1600-1.
55 Copeland RA, Char DH. Limbal autograft reconstruction after squamous cell carcinoma. Am $\mathcal{F}$ Ophthalmol 1990;110: $412-15$

56 Coster DJ, Aggarwal RK, Williams KA. Surgical management of ocular surface disorders using conjunctival and stem cell allografts. $\mathrm{Br} \mathcal{F}$ Ophthalmol 1995;79: 977-82.

57 Mauriello JA, Napolitano J, McLean I. Actinic keratosis and dysplasia of the conjunctiva: a clinicopathological study of 45 cases. Can $\mathcal{F}$ Ophthalmol 1995;30:312-16. 